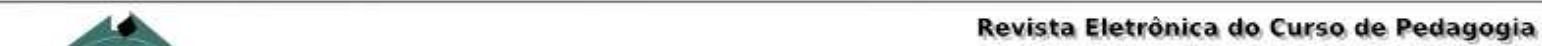 \\ 1.4PG

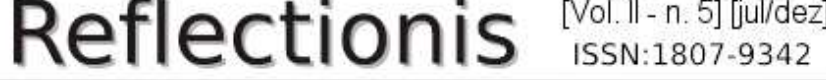

\section{ARQUITETURA E ESPAÇO ESCOLAR NA PRODUÇÃO DE SUBJETIVIDADES}

\author{
Elizabeth Gottschalg Raimann * \\ Cristiane Raimann ${ }^{* *}$
}

\begin{abstract}
RESUMO A discussão em torno da cidade contemporânea se torna instigante na medida em que considerada artefato cultural pode ser analisada pelas práticas da sociedade capitalista enquanto uma "arte das distribuições". Nesse viés, esta sociedade é disciplinar e a sua arquitetura pode determinar e separar os espaços nos quais os indivíduos devem viver e trabalhar, produzindo discursos e práticas de subjetivação por meio de uma tecnologia especifica desenvolvida por estratégia de controle social. Objetiva-se problematizar a escola enquanto arquitetura e espaço que ocupa no tecido urbano na produção de discursos e práticas. A análise deu-se a partir da observação de uma escola municipal localizada no interior de Goiás. As descrições do espaço embasadas nas contribuições de Foucault buscam referências para estabelecer como se efetivam relações de poder-saber, como as arquiteturas das instituições da sociedade disciplinar viabilizam alguns dispositivos que objetivam a disciplinarização. Assim, além de conteúdos e práticas desenvolvidas no interior da escola, o aspecto da arquitetura escolar e o espaço ocupado na cidade contribuem na produção de sujeitos, subjetivando-os e adequando-os à sociedade capitalista.
\end{abstract}

Palavras-chave: arquitetura - espaço escolar- produção de subjetividades

ABSTRACT: The discussion on the contemporary city has become stimulating in that, considered a cultural artifact, it can be analysed by the practices of the capitalistic society as an "art of distributions". Under this point of view, this society is disciplined and its architecture may determine and separate spaces at which the individuals must live and work, producing discourses and subjectivation practices through a specific technology developed by social control strategy. The aim of this paper is to problematise the school as architecture and space that it occupies in the urban tissue when producing discourses and practices. The analysis was carried out from the observation of a municipal school located in the countryside of Goiás. The descriptions of space based on the contributions of Foucault search for references in order to determine how the relationships of power-knowing are put into effect, how the architectures of the institutions from the disciplined society make feasible some mechanisms which aim at disciplinarization. Thus, besides the contents and practices developed inside the school, the aspect of the school architecture and the space occupied in the city contribute to the production of subjects, subjectivating them and adjusting them to the capitalistic society.

Key-words: architecture - school space - production of subjectivities

\footnotetext{
*Mestre em Educação - Docente do Curso de Pedagogia do CAJ/UFG. elizabethraimann@ yahoo.com.br.

** Discente do Curso de Arquitetura e Urbanismo/ULBRA
} 


\section{Introdução}

O presente trabalho embasado nas contribuições de Michel Foucault, Augustín Escolano e Antonio Viñao Frago situa-se na linha de pesquisa voltada para as práticas de subjetivação na educação, sendo integrado ao grupo TEIA - grupo multidisciplinar de estudos em análise do discurso de Jataí - AD. As discussões deste artigo foram apresentadas no SILACC - Simpósio Internacional Latino Americano Cultura e Cidades dentro do eixo projeto, cultura e projetualidade na cidade contemporânea propondo uma reflexão e debate numa perspectiva interdisciplinar da problemática da cultura e da espacialidade da cidade, suas continuidades e transformações.

Objetiva-se problematizar a escola como arquitetura e espaço que ocupa no tecido urbano na produção de discursos e de práticas. A descrição minuciosa do espaço tem sua relevância assegurada por refletir a busca, em Foucault, de referências para estabelecer como se efetivam relações de poder-saber, ou seja, como as arquiteturas das instituições da sociedade disciplinar viabilizam alguns dos mecanismos, dispositivos, que objetivam a disciplinarização. Foucault utiliza-se da arquitetura do Panóptico de Bentham exemplificando-o como uma construção favorável à observação e a um mecanismo eficiente de poder, um laboratório de poder, na produção de saber. A disciplinarização que ocorre no espaço escolar se dá mediante uma relação de poder-saber, que além de produzir o aluno/sujeito, produz discursos no campo da pedagogia, por exemplo, as teorias curriculares e a própria arquitetura escolar.

Dessa forma, pretende-se discutir no primeiro momento a importância da arquitetura escolar na política educacional. A seguir, trazer as contribuições do pensamento de Foucault para uma reflexão da escola na sociedade contemporânea disciplinar. E na seqüência, estabelecer as práticas de subjetivação presentes na arquitetura e no espaço escolar.

\section{A arquitetura escolar e a política educacional}

O interesse pela arquitetura escolar, principalmente no Brasil, como um objeto de estudo da educação ainda é, de certa forma, recente e localizado em determinados estados do Brasil, por exemplo, Buffa (2005) nas escolas de São Paulo, Dórea (2000) nas escolas do Rio de Janeiro e da Bahia, e Loureiro e Amorim (2001) analisando a influência da arquitetura social de Richard Neutra em prédios escolares de Pernambuco. 
Por sua vez, Frago e Escolano (2001) discutem a arquitetura escolar espanhola como programa de uma política educacional. Tal discussão permite fazer aproximações com a realidade brasileira, uma vez que argumentam "o espaço escolar tem de ser analisado como um construto cultural que expressa e reflete, para além de sua materialidade, determinados discursos" (p.26). E quanto à arquitetura escolar defendem que:

É também por si mesma um programa, uma espécie de discursos que institui na sua materialidade um sistema de valores, como os de ordem, de disciplina e vigilância, marcos para a aprendizagem sensorial e motora, e toda uma semiologia que cobre diferentes símbolos estéticos, culturais e também ideológicos (FRAGO e ESCOLANO, 2001, p.26).

A arquitetura escolar no Brasil, início da República aos dias atuais, não se apresenta com as mesmas características, uma vez que os projetos arquitetônicos estão implicitamente ligados às questões políticas tanto educacionais quanto econômicas.

Lage (2007), mediante as contribuições dos estudos de Ester Buffa e Rosa Fátima Souza, apresenta como as diferentes concepções de urbanidade, higiene e educação influenciaram a arquitetura e a construção dos prédios escolares no início do século XX e as transformações ocorridas posteriormente. Se antes havia uma arquitetura neoclássica - própria da $1^{\mathrm{a}}$. Revolução Industrial -, prevalecendo prédios imponentes com eixos simétricos, entre outros aspectos; à medida que a arquitetura avança de uma concepção tradicional de educação para uma visão voltada ao processo de ensino-aprendizagem centrado no aluno, passando ele a ser o foco das atenções conforme proposta do movimento da Escola Nova, a arquitetura segue essas tendências. Nesse aspecto, os prédios escolares também vão se tornando mais modernos, construídos com novos materiais, como o concreto armado, edificações de forma geométrica simples, sem ornamentação e com grandes aberturas envidraçadas.

Com a política desenvolvimentista do governo brasileiro a partir dos anos de 1950, as escolas também vão se adequando às novas exigências econômicas, sendo efetivados projetos mais utilitários, baratos e de construção rápida atendendo uma demanda mais quantitativa do que qualitativa.

Escolano (2001), ao descrever a arquitetura escolar decorrente do início do século XX, numa visão modernista, pondera sobre as correspondências entre essa e os postulados do higienismo, a racionalidade panóptica e o movimento educacional da época. Ao considerar os 
espaços escolares como elementos significativos do currículo, apresentam-se tais espaços educativos como aqueles que "abrigam a liturgia acadêmica e estão dotados de significados, e transmitem uma importante quantidade de estímulos, conteúdos e valores do chamado currículo oculto, ao mesmo tempo em que impõem suas leis como organizações disciplinares" (ESCOLANO, 2001, p.27).

Escolano (2001) aproxima a planificação panóptica às propostas tayloristas do espaço escolar, ou seja, uma racionalização do espaço, dos movimentos, dos costumes e dos corpos, seguindo assim as orientações de uma visão positivista das ciências humanas e contribuindo para "tecnificar com base em fundamentos 'científicos' esses paradigmas espaciais baseados na setorialização" (p.28).

Dessa forma, ao considerar a disposição espacial da escola no tecido de um espaço urbano determinado, os autores citados, Frago e Escolano (2001), defendem que isso pode gerar uma imagem da escola como centro de um urbanismo racionalmente planificado ou como uma instituição marginal. Num modelo de setorialização da população instituído pelo positivismo sociológico, cada segmento tem a sua própria área espacial, como no caso "[d]os projetos mais ou menos utópicos de reforma social ou de criação de uma nova sociedade" (Frago, 2001, p.85). Frago exemplifica com o "familistério" de Guisa - construção de creche e do conjunto escolar com teatro para os operários por um industrial de Guisa inspirado no "falanstério" de Fourier, na França.

Na discussão entre urbanismo e educação, Frago apresenta que a idéia de manter as escolas nos bairros periféricos como estava previsto a principio, ao se buscar uma higiene tanto física quanto moral, passou a ser revista. No planejamento das construções escolares, procurou-se aproximar estas às residências das crianças e optar pelas proximidades com jardins, praças e ruas largas, aliando-se três fatores: "o educativo - distanciamento em relação ao barulho, ambiente propício ao estudo, fácil acesso à natureza -; o higiênico e o econômico - menor preço nos terrenos" (FRAGO, 2001, p.85).

Se no inicio do século XX o discurso higienista prevalecia, de certa forma, para o planejamento urbano para a educação, após 100 anos percebe-se uma mudança significativa. Atualmente, prevalece o discurso econômico em detrimento da própria qualidade da educação. O discurso da sociedade capitalista neoliberal para a educação hoje apregoa que ela é um bem de consumo.

Analisando a organização da cidade nessa sociedade neoliberal percebem-se as 
ambigüidades presentes, pois a localização da escola pode delimitar e classificar a clientela atendida. Ou seja, quanto mais próxima ao centro administrativo e comercial da cidade melhores e mais amplas serão as escolas, os alunos atendidos serão os de classe mais privilegiada e terão melhores oportunidades; enquanto as escolas de periferia, edificadas a partir do uso racional do material, destinam-se aos filhos de operários e aos que têm subempregos, ficando tal espaço restrito a esses alunos de classe popular, que já foram preparados a ser disciplinados para adequar-se ao mercado.

A disciplinarização tanto do corpo quanto do espaço será discutida a seguir embasada pelas contribuições de Foucault.

\section{Foucault e a sociedade disciplinar}

Em suas obras, Foucault problematiza, entre outros aspectos, as múltiplas dinâmicas do poder. A sua preocupação está não em definir o que é o poder, ou de onde ele provém, porém como o poder se exerce, o que faz com que ele funcione.

Para Foucault, a questão do poder "é que ele coloca em jogo relações entre indivíduos (ou entre grupos)" (1995, p. 240), pois semelhante a uma rede de fios que se entrelaçam e não se sabe o seu início, assim o poder se estende por todos os lados, a ninguém pertencendo em específico, pois onde se encontra também é exercido. Como argumenta: "ninguém é, propriamente falando, seu titular; e, no entanto, ele sempre se exerce em determinada direção, com uns de um lado e outros de outro; não se sabe ao certo quem o detém; mas se sabe quem não o possui” (2001a, p.75).

Nessa perspectiva, o poder "é um feixe de relações mais ou menos organizado, mais ou menos piramidalizado, mais ou menos coordenado" (FOUCAULT, 2001a, p.248). Assim, o poder não existe enquanto não se efetivar. Não é propriedade de ninguém, como se fosse privilégio poder utilizá-lo ou não.

O poder, tanto acontece de cima para baixo, como de baixo para cima, e se irradia em todas as direções, não estando localizado, nem possuindo limites. Nesse sentido, "o poder deve ser analisado como algo que circula, ou melhor, como algo que só funciona em cadeia. Nunca está localizado aqui ou ali [...]. O poder funciona e se exerce em rede" (FOUCAULT, 2001a, p. 183).

Dessa forma, para Foucault, o poder não atua pedagogicamente somente de cima, 
mediante o Aparelho de Estado, mas também atua na própria sociedade de forma disciplinar através da linguagem, das convivências sociais, dos tabus, da moral e do discurso científico. Esse poder, por meio de seus mecanismos sutis, tecnologias ou dispositivos - que se caracterizam por mecanismos de controle como: o quadriculamento do espaço, do controle do tempo, o olhar que vigia e pune, as regras que normalizam a sociedade e o indivíduo - forma, organiza, circula e gera saber, constituindo tanto o homem quanto a mulher de forma a objetivá-los e a sujeitá-los. Ou seja, mediante a relação poder-saber, o indivíduo se constitui tanto em objeto de conhecimento a ser dominado quanto em objeto a ser produzido pelo discurso - tornar-se sujeito: estar sujeito a alguém mediante o poder do controle e da dependência, como é estar preso a si mesmo a partir de uma identidade que se construiu socialmente.

A observação, ou o olhar hierárquico, é caracterizada por técnicas de vigilância sobre os corpos. Esse olhar que a tudo vê, pretende ao mesmo tempo oferecer espaço de produtividade e de saber. Foucault, exemplificando a observação como um mecanismo eficiente, utiliza o que acontece no interior do hospital, da oficina e da escola, e comenta:

As instituições disciplinares produziram uma máquina de controle que funcionou como um microscópio do comportamento; as divisões tênues e analíticas por elas realizadas formam, em torno dos homens, um aparelho de observação, de registro e de treinamento (FOUCAULT, 2001b, p.145).

Por um aparelho de observação, Foucault exemplifica fazendo menção ao Panóptico de Bentham. O Panóptico era uma construção cuja periferia consistia em anel, no centro uma torre com janelas grandes para o interior do anel. A construção periférica era dividida em celas que possuíam duas janelas, uma voltada para a torre e a outra para o exterior, permitindo o traspassar da luz por entre as janelas da cela. Esta construção se caracterizou por ser uma estrutura arquitetônica que abrigava presidiários e viabilizava a sua autodisciplina, pois, ao mesmo tempo em que esses eram vigiados sem saberem disso, também se regulavam a si mesmos; da mesma forma, acontecia com os próprios vigilantes daqueles presidiários, eram observados por seus supervisores sem o saberem que, de forma semelhante, também se autodisciplinavam. Esse dispositivo de observação, segundo Foucault, já era utilizado pela Escola Militar de Paris em 1751.

Um outro entendimento para o Panóptico seria o da perspectiva foucaultiana, o de ser 
"máquina de fazer experiências, modificar o comportamento, treinar ou retreinar os indivíduos [...] tentar experiências pedagógicas" (Foucault, 2001b, p. 168). Esse dispositivo de observação seria algo parecido com um laboratório de poder na produção de saber. Assim, o saber, por sua vez, realimentado pelo poder, conduziria a essa relação poder-saber que produz discursos e sujeitos. Isso é reiterado por Foucault ao explicar o Panóptico como um laboratório de poder:

O Panóptico funciona como uma espécie de laboratório de poder. Graças a seus mecanismos de observação, ganha em eficácia e em capacidade de penetração no comportamento dos homens; um aumento de saber vem se implantar em todas as frentes do poder, descobrindo objetos que devem ser conhecidos em todas as superfícies onde este se exerça (FOUCAULT, 2001b, p.169).

Segundo Foucault, não é possível separar o poder do saber, estes estão interligados, interdependentes. Assim, afirma "o exercício do poder cria perpetuamente saber e, inversamente, o saber acarreta efeitos de poder" (2001a, p.142). E esses elementos - poder e saber - materializam-se por meio de práticas e discursos que produzem regimes de verdade.

A tecnologia do poder, na perspectiva foucaultiana, atua na sua forma "capilar de existir, no ponto em que o poder encontra o nível dos indivíduos, atinge seus corpos e vêm se inserir em seus gestos, suas atitudes, seus discursos, sua aprendizagem, sua vida quotidiana" (ibidem, p.131).

Ao mesmo tempo em que Foucault busca perceber "os pontos pelos quais o discurso se transforma em, através de e a partir das relações de poder" (2001a, p.158), considera que essas mesmas relações de poder levam ao saber mediante estratégias de uma mecânica — as disciplinas - que levam à disciplinarização tanto do saber como daquela que incide nos corpos e os transforma em corpos dóceis e produtivos (2001b).

O deslocamento do poder proposto por Foucault, atuando em sua capilaridade por meio de sua mecânica e de sua discursividade, na qual o saber e os sujeitos são produzidos, encaminham-nos sugestivamente para uma análise da escola e do seu interior; pois, nesse espaço, elabora-se um discurso pedagógico e um sujeito para a sociedade moderna capitalista, disciplinar.

Fala-se, freqüentemente, das invenções técnicas do século XVIII as tecnologias químicas, metalúrgicas etc. - mas, erroneamente, nada se diz da invenção técnica dessa nova maneira de gerir os homens, controlar suas multiplicidades, utilizá-las ao máximo e 
majorar o efeito útil de seu trabalho e sua atividade, graças a um poder suscetível de controlá-los. Nas grandes oficinas que começam a se formar, no exército, na escola, quando se observa na Europa um grande progresso da alfabetização, aparecem essas novas técnicas de poder que são uma das grandes invenções do século XVIII (FOUCAULT, 2001a, p.105).

A sociedade moderna, com suas transformações econômicas, sociais e políticas, utilizase da educação, com seu poder disciplinar de levar os indivíduos a serem permanentemente vigiados e localizados, para favorecer principalmente as relações úteis e produtivas.

Segundo análise de Foucault, a escola, como instituição, assemelha-se a um 'bloco' na medida em que nela há adequação das competências, relações de comunicação e relações de poder que formam um sistema regulado e coeso. Como argumenta:

Há também 'blocos' [...]. Seja, por exemplo, uma instituição escolar: sua organização espacial, o regulamento meticuloso que rege a vida interior, as diferentes atividades aí organizadas, os diversos personagens que aí vivem e se encontram, cada um com sua função, um lugar, um rosto bem definido - tudo isto constitui um "bloco" de capacidade-comunicação-poder. A atividade que assegura o aprendizado e a aquisição de aptidões ou de tipos de comportamento aí se desenvolve através de todo um conjunto de comunicações reguladas (lições, questões e respostas, ordens, exortações. Signos codificados de obediência, marcas diferenciais do "valor" de cada um e dos níveis de saber) e através de toda uma série de procedimentos de poder (enclausuramento, vigilância, recompensa e punição, hierarquia piramidal) (FOUCAULT, 1995, p.241).

A tal sistema podemos dar o nome de currículo, pois, se entendido como uma trajetória que envolve toda a dinâmica na e para a escola, tem a finalidade de produzir identidades e subjetividades. E assim, o espaço escolar não é singular, pois análogo a outras instituições hospital e prisão - produz regimes de verdade, tecnologias de controle e identidades.

Com essas referências, passa-se a seguir à análise de uma instituição escolar considerando sua arquitetura, sua organização espacial com salas e dependências e sua localização no tecido urbano.

\section{As práticas de subjetivação presentes na escola}

A partir de um estudo voltado para a análise da escola e de seu currículo para a Educação de Jovens e Adultos, numa perspectiva foucaultiana, realizou-se uma pesquisa 
numa escola municipal de uma cidade de porte médio do sul de Goiás.

Como procedimento de pesquisa utilizou-se a observação da escola considerando seu espaço exterior e interior. No aspecto arquitetônico, procurou-se perceber a construção e a disposição dos prédios que comportam as salas de aulas e outras dependências, assim como as aberturas, portas e janelas que permitem a visibilidade e o controle dos que circulam no interior e no exterior da escola e normatizam os que ali trabalham e estudam.

No espaço territorial, buscou-se analisar o espaço ocupado pela escola em relação ao bairro e à cidade, bem como o espaço ocupado pelos corpos - do corpo técnicoadministrativo, do corpo docente e discente na escola.

A escola está arquitetonicamente projetada para um espaço disciplinar. Sua arquitetura evidencia um conceito racionalista que tem como principais características: linguagem formal, sem ornamentação, de formas simples e bem geométricas, com aberturas horizontais, integração dos espaços internos e externos, aberturas envidraçadas e, ainda, grandes corredores para uma boa circulação, utilizando o funcionalismo arquitetônico .

O conjunto dos prédios escolares é organizado pela disciplina como um espaço de controle. Na estrutura física, tem-se o espaço distribuído para a direção, a secretaria, a biblioteca, a sala de professores e as salas de aulas. Nessas últimas, o próprio interior da sala de aula é ordenado espacialmente, criando um espaço útil. Assim, cada um dos alunos ocupa seu lugar específico, bem como os professores.

Ao tratar do quadriculamento ou "arte das distribuições" em 'Os corpos dóceis', Foucault observa:

As disciplinas, organizando as 'celas', os 'lugares' e as 'fileiras' criam espaços complexos: ao mesmo tempo arquiteturais, funcionais e hierárquicos. São espaços que realizam a fixação e permitem a circulação [...], marcam lugares e indicam valores; garantem a obediência dos indivíduos, mas também uma melhor economia do tempo e dos gestos (2001b, p. 126).

As disposições arquitetônicas presentes em uma diferenciação da volumetria, prédio levemente mais alto, facilita o seu destaque entre os edifícios para demonstrar sua importância no espaço escolar. Este destinado à direção possibilita a observação e o controle mais efetivos que também são estendidas aos três prédios onde se localizam as salas de aula. Entre os prédios das salas de aula, existem corredores largos que permitem o acesso às salas, o prédio central abriga um corredor menor que dá acesso aos banheiros. 
As salas de aula são idênticas. A porta de acesso a cada sala fica voltada para o corredor e o quadro-de-giz está ao lado dessa porta, possibilitando uma disposição mais dinâmica e oferecendo aos professores uma visão do movimento do pequeno pátio entre os prédios e como controlar a entrada e a saída de alunos. As janelas das salas ficam em ambos os lados; do lado da porta janelas altas e menores - para não possibilitar a visão da circulação de pessoas, favorecendo maior concentração e aproveitamento da ventilação e da luz natural - e do lado oposto, janelas grandes. Os prédios laterais possuem grandes janelas voltadas para uma área de pouca circulação, somente do prédio do meio, também de salas de aula, é possível olhar o interior das salas com mais facilidade.

Essa descrição minuciosa do espaço tem sua relevância assegurada por refletir a busca em Foucault de referências para estabelecer como se efetivam relações de poder-saber, ou seja, como as arquiteturas das instituições da sociedade disciplinar viabilizam alguns dos mecanismos ou dispositivos de poder-saber que objetivam a disciplinarização.

A tais dispositivos Foucault se refere ao dizer "o sucesso do poder disciplinar se deve, sem dúvida, ao uso de instrumentos simples: o olhar hierárquico, a sanção normalizadora e sua combinação num procedimento que lhe é específico, o exame” (2001b, p. 143).

Apontando para a percepção do panóptico é possível dizer que no interior da escola pesquisada também há mecanismos de controle semelhantes e mais sutis. É o que se pode verificar diante do modo como a escola observa e organiza o seu interior e o seu exterior.

De seu interior, ela disciplina o comportamento das pessoas que nela circulam, por meio do olhar observador possível das janelas ou da porta do prédio administrativo, que dão para o pátio interno da escola, no caso. Por exemplo, o comportamento dos alunos, ao fazê-los cumprir as regras de conduta social ao serem pegos em brigas e discórdias; a organização e a disciplina do tempo do trabalho, tanto de alunos quanto de funcionários, por meio de um quadro demonstrativo com os respectivos horários de aulas e de serviços.

Esse quadro, afixado visivelmente no hall de entrada da escola com as tarefas diárias e semanais dos zeladores; e o outro, com o horário de aulas dos professores dos turnos matutino e vespertino, possibilitam a quem interessar tanto o controle dos corpos - horário de trabalho - quanto do saber - horário das disciplinas ministradas.

Assim, pela observação, por meio dos pontos estratégicos, tanto alunos quanto professores e funcionários observam e são observados pelos seus movimentos externos no pátio no horário de aula e no intervalo. 
Na disposição arquitetônica, relacionam-se o poder e o saber, como destaca Foucault em seu texto 'Os recursos para o bom adestramento'. Nesse texto, o autor analisa a disposição do acampamento militar e afirma que essa disposição se tornou um modelo de observatório mediante sua geometria e por meio da qual se desenha uma "rede dos olhares que se controlavam uns aos outros" (2001b, p.144); esse modelo se estendeu posteriormente ao urbanismo quando da construção de hospitais, de asilos, de casa de educação, entre outros. A partir desse padrão de vigilância hierarquizada, desenvolveu-se uma problemática como afirma Foucault:

[...] uma arquitetura que não é mais feita simplesmente para ser vista [...], ou para vigiar o espaço exterior [...], mas para permitir um controle interior articulado e detalhado - para tornar visíveis os que nela se encontram; mais geralmente, a de uma arquitetura que seria um operador para a transformação de indivíduos: agir sobre aqueles que abriga, dar domínio sobre seu comportamento, reconduzir até eles os efeitos de poder, oferecê-los a um conhecimento, modificá-los (FOUCAULT, 2001b, p. 144).

Esse espaço arquitetônico escolar apresenta seus micropoderes, pois, assim como são observados os alunos, os professores e os demais técnicos pela direção, da mesma forma todos se observam, controlam-se, normatizando as condutas e os múltiplos afazeres. Esse controle, que é externo, vai sendo internalizado de forma que cada um passa a se autodisciplinar.

Sobre essa visibilidade e seus efeitos de sujeição, Foucault irá afirmar:

Quem está submetido a um campo de visibilidade, e sabe disso, retoma por sua conta as limitações do poder; fá-las funcionar espontaneamente sobre si mesmo; inscreve em si a relação de poder na qual ele desempenha simultaneamente os dois papéis; torna-se o princípio de sua sujeição (2001 b, p. 168).

E Escolano, por sua vez, a esse respeito, acrescenta:

A "espacialização" disciplinar é parte integrante da arquitetura escolar e se observa tanto na separação das salas de aulas (graus, sexos, características dos alunos) como na disposição regular das carteiras (com corredores), coisas que facilitam, além disso, a rotina escolar das tarefas e a economia do tempo. Essa "espacialização" organiza minuciosamente os movimentos e os gestos e faz com que a escola seja um 'continente de poder' (2001, p. 27-8). 
Da mesma forma que o espaço arquitetônico permite o quadriculamento, o espaço territorial, objeto da análise seguinte, também o permite igualmente, porém de forma mais incisiva sobre os corpos. Seria um mapeamento daqueles que estão na escola. O mapeamento é, de acordo com Foucault, utilizado para situar os corpos num determinado território ou para se referir a um levantamento estatístico.

Foucault utiliza o termo geográfico território como uma metáfora, no sentido de que "é uma noção jurídico-política: aquilo que é controlado por certo tipo de poder" (2001a, p.157). Considerando o território como um mapa, tal "território" se torna um instrumento de saberpoder. Nesse sentido, o espaço territorial da escola pode ser uma delimitação do campo que é ocupado pelo corpo técnico-administrativo, do corpo discente e docente na escola e em sala de aula, bem como o espaço ocupado pela escola no espaço urbano.

Ao considerar a localização da Escola na distribuição do tecido urbano, observa-se primeiramente que ela própria está enquadrada em bairro periférico. Essa localização delimita e classifica a clientela à qual irá atender. Devido a sua localização adjacente à zona rural, também, recebe crianças provenientes dos sítios do entorno da cidade; e, no turno noturno, freqüentam a escola, na grande maioria, pessoas jovens e adultas de baixa renda, trabalhadores braçais e domésticas.

Nesse sentido, esse mapeamento permite levantar discursos em torno desse alunado e delinear um currículo oficial e outro "oculto".

No interior da escola, dá-se outra delimitação à medida que se demarca cada indivíduo no seu lugar, ou seja, considerados como um conjunto de corpos, tanto o corpo técnicoadministrativo, quanto o corpo docente e discente têm seu espaço específico reservado.

O corpo técnico-administrativo está separado no prédio da administração, e nesse também cada indivíduo tem seu próprio espaço definido com sua sala, sua mesa e cadeira, sabendo que tarefas cumprir. Cada tarefa está ligada a uma função administrativa específica que regula, cumpre e faz cumprir as diretrizes das secretarias municipal e estadual.

O corpo docente também tem seu lugar definido, tanto na sala de professores, ocupandoa para o descanso ou para a realização de tarefas, quanto nas salas de aula, junto ao quadrode-giz, ensinando ou circulando por entre os alunos, verificando o aprendizado, produzindo discursos pedagógicos e identidades dos alunos, subjetivando-os.

O corpo discente está ordenado e quadriculado nos espaços internos da sala de aula, onde mesas e cadeiras estão enfileiradas para, ao nelas se sentarem os alunos, possam se 
tornar peças de uma máquina multissegmentar. Para Foucault, o corpo se constitui como peça dessa máquina e "a disciplina não é mais simplesmente uma arte de repartir os corpos, de extrair e acumular o tempo deles, mas de compor forças para obter um aparelho eficiente" (2001b, p. 138).

Essa composição de forças se daria à medida que a disciplina combinasse os respectivos tempos de cada um dos corpos e os articularia para a obtenção de um efeito mais que satisfatório, ou seja, "o tempo de uns deve-se ajustar ao tempo de outros de maneira que se possa extrair a máxima quantidade de forças de cada um e combiná-la num resultado ótimo" (FOUCAULT, ibidem, p.139). É o caso, por exemplo, das tarefas escolares realizadas em conjunto e que exigem delimitação de tempo ou como os exercícios físicos seqüenciais em grupo.

A partir do princípio da localização imediata ou quadriculamento, escreve Foucault “importa estabelecer as presenças e as ausências, saber onde e como encontrar os indivíduos, instaurar as comunicações úteis, interromper as outras, poder a cada instante vigiar o comportamento de cada um, apreciá-lo, sancioná-lo, medir as qualidades ou os méritos" (ibidem, p.123). A distribuição dos alunos na escola também se dá mediante a classificação que os examina, analisa-os e os separa conforme seus conhecimentos ou idade.

\section{Considerações finais}

Neste trabalho, buscou-se situar a arquitetura escolar como um componente importante no planejamento e no currículo escolar, situando-a nas políticas governamentais para a educação. De igual importância, temos as práticas de disciplinarização presentes na escola e materializadas por meio da arquitetura escolar, do controle do tempo e do espaço, do olhar que vigia e regula.

A análise dos dados permitiu considerar que fazem parte do currículo, além de conteúdos escolares e práticas desenvolvidas no interior da escola, o aspecto da arquitetura escolar e do espaço ocupado pela escola na cidade; e que tais elementos contribuem na produção de sujeitos, subjetivando-os e adequando-os à própria sociedade capitalista.

Dessa forma, não só a educação não é neutra, mas todo o conjunto de prédios escolares, com sua arquitetura e funcionalismo, e o espaço territorial ocupado pela escola no tecido urbano não são neutros, produzem discursos e sujeitos, formando e conformando, segundo uma lógica neoliberal, os que nela trabalham e estudam. 


\section{Referências Bibliográficas}

BUFFA, Ester. Práticas e fontes de pesquisa em história da educação. In: História da educação em perspectiva. Ensino, pesquisa, produção e novas investigações. Gatti Junior, Décio e Inácio Filho, Geraldo (orgs.). Campinas: Autores Associados, Uberlândia; EDUFU,2005.

DÓREA, Célia Rosangela Dantas. Anísio Teixeira e a arquitetura escolar: planejando escolas, construindo sonhos. Revista da FAEEBA. Salvador, n.13, jan/jun, p.151-160, 2000. Disponível: http://www.prossiga.br/anisioteixiera/fran/artigos/dorea.html

ESCOLANO, Augustín. Arquitetura como programa. Espaço-escola e currículo. In: Currículo, espaço e subjetividade: a arquitetura como programa. Frago, Antonio Viñao e Escolano, Augustín. Trad. Alfredo Veiga-Neto. 2.ed. Rio de Janeiro: DP\&A,2001. pp.19-57

FOUCAULT, Michel. O sujeito e o poder. In: Uma trajetória filosófica: para além do estruturalismo e da hermenêutica. Rabinow, Paul e Dreyfus, Hubert. Tradução Vera Porto Carrero.. Rio de Janeiro: Forense Universitária,1995. pp. 231-249

FRAGO, Antonio Viñao e ESCOLANO, Augustín . Currículo, espaço e subjetividade: a arquitetura como programa. Trad. Alfredo Veiga-Neto. 2.ed.Rio de Janeiro: DP\&A, 2001.

FRAGO, Antonio Viñao. Do espaço escolar e da escola como lugar: propostas e questões. In: Currículo, espaço e subjetividade: a arquitetura como programa. Frago, Antonio Viñao e Escolano, Augustín. Trad. Alfredo Veiga-Neto. 2.ed.. Rio de Janeiro: DP\&A, 2001. pp. 62139

LAGE, Ana Cristina Pereira (2007). Arquitetura escolar-verbete. http://www.histedbr.fae.unicamp.br/ (consulta 09/07/2007)

LOUREIRO, Claudia e AMORIM, Luiz (2002) Por uma arquitetura social: a influencia de Richard Neutra em prédios escolares no Brasil. http://www.vitruvius.com.br/arquitextos/arq020/arq020_03.asp. (consulta 09/07/2007) $2001^{\mathrm{a}}$

Microfísica do poder. 16. ed. Organizador Roberto Machado. Rio de Janeiro: Graal,

SOUZA, Rosa Fátima de. Templos de civilização: a implantação da escola primária graduada no Estado de São Paulo (1890-1910). São Paulo: UNESP, 1998.

Vigiar e punir: o nascimento da prisão. 24. ed. Tradução Raquel Ramalhete. Petrópolis:

Vozes, 2001b 